\title{
Microbiota ileal de frangos de corte submetidos a diferentes dietas
}

\author{
Ione Iolanda dos Santos ${ }^{1}$, Gertrudes Corção ${ }^{1}$, Alexandre de Mello Kessler ${ }^{1}$, Vani dos Santos \\ Laranjeira $^{1}$, Marla Sonaira Lima ${ }^{1}$
}

${ }^{1}$ Universidade Federal do Rio Grande do Sul-UFRGS, Porto Alegre, RS.

RESUMO - Este estudo foi conduzido para analisar as alterações do perfil microbiano da digesta ileal de frangos de corte alimentados com dietas contendo diferentes níveis de energia e aditivos. Foram preparadas duas dietas: uma à base de milho e farelo de soja com nível de energia padrão e outra de baixa energia com milho e os farelos de soja e trigo. Para cada nível de energia, foram ou não acrescentados o probiótico Enterococcus faecium; as enzimas xilanase, amilase mais $\beta$-glucanase; e a combinação do probiótico com as enzimas, resultando em 8 tratamentos. As aves foram distribuídas em delineamento inteiramente ao acaso com arranjo fatorial $2 \times 4$ e cada tratamento teve 5 repetições de 12 aves. Aos 19 dias, uma ave de cada repetição foi abatida e o conteúdo ileal coletado e armazenado a $-24{ }^{\circ} \mathrm{C}$. Foram feitas as extrações do DNA do microrganismo probiótico e da microbiota ileal utilizando-se o kit QIAamp DNA Stool, conforme as recomendações do fabricante. As amostras extraídas foram amplificadas por PCR. Utilizou-se a técnica de eletroforese em gel com gradiente desnaturante para caracterização do perfil da microbiota ileal e do probiótico utilizado nas dietas. Todos os tratamentos apresentaram padrões de amplicons diferentes, com exceção das enzimas isoladas e em combinação nas dietas com energia padrão. $O$ perfil do microrganismo probiótico esteve ausente em todas as dietas. Os aditivos introduzidos às dietas foram capazes de alterar a microbiota digestiva do lúmem ileal, porém o probiótico utilizado não foi capaz de colonizar o trato ileal dos frangos de corte.

Palavras-chave: DGGE, DNA, enzimas, probiótico, trigo

\section{Ileal microbiota of broilers fed different diets}

\begin{abstract}
The study was conducted to analyze alterations in the microbiological profile of the ileal digesta of broilers fed different levels of energy and additives. A standard diet based on corn-soybean meal and a low energy diet based on corn, soybean and wheat bran were prepared. Either Enterococus faecium probiotic or xylanase, amylase plus $\beta$-glucanase enzymes or the mix of probiotic and exzymes were added or not to each energy level, resulting in eight treatments. Birds were distributed in a $2 \times 4$ factorial arrangement in a completely randomized design, and each treatment had 5 replications of 12 birds. One bird of each repetition was slaughtered at 19 days of age and the ileal contents were collected and stored at $-24{ }^{\circ} \mathrm{C}$ until analysis. DNA was extracted from the microorganism probiotic and ileal content using the QIAamp DNA Stool kit following the recommendations of the manufacturer. The extracted samples were amplified by PCR and the ileal microbiota and probiotic profiles were characterized using denaturing gradient gel electrophoresis. The results show that all treatments resulted in different profiles of amplicons, except for enzymes alone or mix with probiotic in the standard energy diet. The probiotic microorganism profile was absent in all diets. The use of additives changed the digestive microbiota in the ileum, although the probiotic was not capable of colonizing the ileum of the birds.
\end{abstract}

Key Words: DGGE, DNA, enzymes, probiotic, wheat

\section{Introdução}

As espécies bacterianas diferem em relação às suas preferências por substratos e suas necessidades para o crescimento. Por isso, a composição química e a estrutura da digesta determinam amplamente a distribuição da microbiota no trato digestório (Apajalahti, 2005). A população bacteriana, em determinado momento, reflete a capacidade de cada grupo bacteriano em competir com outros grupos frente ao sistema de defesa e em determinadas condições físicas e químicas do meio. Por isso, as mudanças na composição da dieta, na densidade de nutrientes, características físicas e no processamento do alimento, o tipo e o nível de aditivo utilizado nas dietas podem ter efeitos significantes sobre a dinâmica da microbiota (Apajalahti et al., 2001; Oviedo-Rondón et al., 2006), o que, por sua vez, influi na habilidade dos animais para digerir e absorver nutrientes. Compreender e monitorar as mudanças 
da ecologia microbiana são pontos importantes para o desenvolvimento de produtos que alterem e regulem as microbiotas, melhorando o desempenho ou reduzindo os efeitos de estresse ou doenças. As mudanças na microbiota intestinal de frangos de corte não são facilmente monitoradas usando-se métodos tradicionais de cultivo (Apajalahti et al., 2001) e uma alternativa é o emprego de técnicas moleculares simples. Um grande avanço no campo da biologia molecular é o uso do gene 16S do rRNA como uma impressão digital capaz de classificar e identificar microrganismos (Hume et al., 2006). Utilizando-se um conjunto de oligonucleotídeos iniciadores para amplificar a região conservada do gene $16 \mathrm{~S}$ do rRNA pela PCR (reação em cadeia da polimerase), obtém-se amplicons que podem ser separados por eletroforese em gel com gradiente desnaturante (DGGE) (Thompson et al., 2008). O DGGE foi utilizado pela primeira vez na década de 90, por Muyzer et al. (1993), para caracterizar microbiotas e, a partir de então, tem sido utilizado como ferramenta para pesquisar componentes de ecossistemas complexos, incluindo a microbiota intestinal de frangos de corte (Oviedo-Rondón et al., 2006; Pedroso et al., 2006). Neste estudo, utilizou-se o DGGE para caracterizar o perfil bacteriano da digesta ileal de frangos de corte e do probiótico utilizado na dieta. O objetivo neste trabalho foi avaliar o efeito que os aditivos probiótico e um complexo enzimático promovem na microbiota ileal de frangos de corte, identificando, nos perfis analisados, o probiótico usado nas dietas experimentais.

\section{Material e Métodos}

O experimento foi conduzido com frangos machos da linhagem Ross de 1 a 19 dias de idade. Durante todo o período experimental, os animais receberam água clorada e ração à vontade.

As dietas experimentais foram constituídas de duas composições: uma com nível de energia padrão (EP), à base de milho e farelo de soja, e outra com baixo nível de energia (BE) (redução de $100 \mathrm{kcal} / \mathrm{kg}$ de EM, em relação à dieta padrão, obtido pela inclusão de farelo de trigo) (Tabela 1). As dietas foram balanceadas, atendendo às exigências nutricionais da espécie, de acordo com as recomendações de Rostagno et al. (2005) (Tabela 1). Cada nível de energia recebeu ou não os aditivos probiótico (Enterococcus faecium) e o complexo enzimático (xilanase, amilase e $\beta$-glucanase) isolados ou em combinação.

O delineamento experimental foi inteiramente ao acaso com arranjo fatorial $2 \times 4$, composto de dois níveis de energia e quatro aditivos, resultando em oito tratamentos, os quais tiveram 5 repetições de 12 aves. Os tratamentos foram assim
Tabela 1 - Composição e níveis nutricionais calculados para as dietas experimentais de frangos de corte

\begin{tabular}{|c|c|c|}
\hline Ingrediente $(\%)$ & $\begin{array}{l}\text { Nível padrão } \\
\text { de energia }\end{array}$ & $\begin{array}{l}\text { Nível baixo } \\
\text { de energia }\end{array}$ \\
\hline Milho & 58,46 & 52,38 \\
\hline Farelo de soja 46 & 34,08 & 32,66 \\
\hline Farelo de trigo & - & 7,54 \\
\hline Óleo de soja & 3,08 & 3,08 \\
\hline Calcáreo & 1,36 & 1,39 \\
\hline Fosfato bicálcico & 1,72 & 1,63 \\
\hline Sal comum & 0,46 & 0,46 \\
\hline Premix vitamínico ${ }^{1}$ & 0,04 & 0,04 \\
\hline Premix mineral ${ }^{2}$ & 0,08 & 0,08 \\
\hline Lisina & 0,29 & 0,30 \\
\hline DL-metionina & 0,27 & 0,28 \\
\hline Inerte 3 & 0,05 & 0,05 \\
\hline Colina & 0,06 & 0,06 \\
\hline Monensina $20 \%$ & 0,05 & 0,05 \\
\hline \multicolumn{3}{|l|}{ Composição calculada } \\
\hline Energia metabolizável $(\mathrm{kcal} / \mathrm{kg})$ & 3050 & 2950 \\
\hline Proteína bruta & 21 & 21 \\
\hline Fibra bruta & 3,25 & 3,75 \\
\hline Cálcio & 0,95 & 0,95 \\
\hline Fósforo disponível & 0,45 & 0,45 \\
\hline Sódio & 0,20 & 0,20 \\
\hline Lisina total & 1,29 & 1,29 \\
\hline Metionina total & 0,57 & 0,57 \\
\hline Triptofano total & 0,27 & 0,27 \\
\hline Colina (mg/kg) & 1500 & 1500 \\
\hline
\end{tabular}

${ }^{1}$ Vit. A - $7.000 \mathrm{UI}$; vit. $\mathrm{D}_{3}-1.400 \mathrm{UI}$; vit. E - $20 \mathrm{UI}$; vit. $\mathrm{K}_{3}-1,5 \mathrm{mg}$; vit. $\mathrm{B}_{1}$ $0,6 \mathrm{mg}$; vit. $\mathrm{B}_{2}-5 \mathrm{mg}$; vit. $\mathrm{B}_{6}-0,6 \mathrm{mg}$; vit. $\mathrm{B}_{12}-10 \mathrm{mg}$; ácido nicotínico - $23 \mathrm{mg}$; ácido pantotênico - $10 \mathrm{mg}$; biotina - 0,02 mg; ácido fólico - 0,25 mg.

${ }^{2}$ Manganês - $60 \mathrm{mg}$; ferro - $25 \mathrm{mg}$; cobre - $6 \mathrm{mg}$; zinco - $40 \mathrm{mg}$; selênio - 0,18 mg; iodo $-0,38 \mathrm{mg}$.

${ }^{3}$ Utilizado nas dietas sem aditivos e substituídos pelos aditvos sós ou em combinação nas demais dietas. Aditivos: Probiótico Enterococcus faecium $10^{10} \mathrm{ufc} / \mathrm{g}(30 \mathrm{~g} / \mathrm{t})$; Complexo enzimático xilanase $(100 \mathrm{~g} / \mathrm{t})$ e amilase $+\beta$-glucanase $(400 \mathrm{~g} / \mathrm{t})$.

constituídos: energia padrão sem inclusão de aditivo; energia padrão mais probiótico; energia padrão mais enzimas; energia padrão mais a combinação de probiótico e enzimas; energia baixa sem a inclusão de aditivo; energia baixa mais probiótico; energia baixa mais enzimas; energia baixa mais a combinação de probiótico e enzimas.

Aos 19 dias uma ave de cada repetição foi abatida, o íleo foi exposto e a digesta foi coletada e armazenada em freezer $\left(-24{ }^{\circ} \mathrm{C}\right)$. Posteriormente, as amostras foram descongeladas, as repetições de cada tratamento reunidas e homogeneizadas para a extração do DNA total.

Para a extração do microrganismo probiótico, $3 \mathrm{~g}$ de probiótico foram adicionados a um tubo de ensaio contendo $10 \mathrm{~mL}$ do meio caldo verde brilhante e cultivado em estufa a $37{ }^{\circ} \mathrm{C}$ por 24 horas. A partir de então, $1,2 \mathrm{~mL}$ do cultivo foi transferido a um eppendorf, centrifugado a $4000 \mathrm{rpm}$ por 2 minutos e coletado o precipitado. Este foi lavado com solução salina $(0,9 \%)$ duas vezes para posterior extração do DNA. A extração do DNA do probiótico, assim como do DNA da microbiota ileal, foi realizada utilizando-se o kit QIAamp DNA Stool (Qiagen ${ }^{\circledR}$, São Paulo, Brasil), seguindo 
as instruções do fabricante. A integridade total do DNA foi checada por eletroforese em gel de agarose $0,8 \% \mathrm{com}$ brometo de etídeo $(0,5 \mu \mathrm{L} / \mathrm{mL})$. As amostras de DNA extraído foram armazenadas a $-10{ }^{\circ} \mathrm{C}$.

Para a amplificação dos fragmentos específicos da região V3 do gene 16S rRNA do microrganismo probiótico e da microbiota ileal, utilizaram-se os oligonucleotídeos iniciadores: BA338fCG (5' CGC CCG CGC GCG GCG GGC GGGGCGGGGGCAGCACGGGGGGACTCCTACGGG3') eUN518r (5' ATT ACC GCG GCT GCT GG3')(Pedroso etal., 2005). A reação em cadeia da polimerase (PCR) foi conduzida em um volume de $25 \mathrm{uL}$ contendo $0,2 \mathrm{mM}$ de cada desoxinucleotídeo trifosfato (dNTP), 2,5 $\mathrm{mM}$ de $\mathrm{MgCl}_{2}$, $5 \mu \mathrm{M}$ de cada oligonucleotídeo iniciador, 2,0 U de Taq DNA polimerase, 2,5 uL tampão DNA polimerase 10X e $200 \mathrm{ng}$ de DNA. A reação em cadeia da polimerase do DNA probiótico e da microbiota ileal foi feita seguindo o protocolo utilizado por Thompson et al. (2008): 1 ciclo de $94^{\circ} \mathrm{C}$ por 3 minutos; 30 ciclos de $94{ }^{\circ} \mathrm{C}$ por 1 minuto, $65{ }^{\circ} \mathrm{C}$ por 1 minuto (diminuindo $0,5^{\circ} \mathrm{C}$ por ciclo) e $72^{\circ} \mathrm{C}$ por 1 minuto; 7 ciclos de $94{ }^{\circ} \mathrm{C}$ por 1 minuto, $55{ }^{\circ} \mathrm{C}$ por 1 minuto e $72{ }^{\circ} \mathrm{C}$ por 1 minuto; 1 ciclo de $72{ }^{\circ} \mathrm{C}$ por 7 minutos. Uma alíquota dos produtos da reação em cadeia da polimerase foi analisada em gel de agarose $0,8 \%$.

A eletroforese em gel com gradiente desnaturante foi conduzida de acordo com as recomendações descritas por Muyzer et al. (1993). Para separar os fragmentos amplificados pela reação em cadeia da polimerase, um gel de $8 \%$ poliacrilamida:bisacrilamida (37:5:1) foi preparado com 15 a $55 \%$ de um gradiente desnaturante, usando duas soluções: solução $100 \%$ de desnaturação contendo $40 \%$ formamida e
$7 \mathrm{M}$ de ureia e solução $0 \%$ desnaturante, sem ureia ou formamida. A DGGE (eletroforese em gel com gradiente desnaturante) foi realizada utilizando-se o equipamento DCode (BioRad) em gel de $16 \mathrm{~cm} \times 16 \mathrm{~cm} \times 0,1 \mathrm{~cm}$ e tampão TAE 1X (a partir de TAE 50X: $20 \mathrm{mM}$ tris-acetato, $10 \mathrm{Mm}$ acetato de sódio, 0,5 mM EDTA - pH 8,0). Um volume de $42 \mu \mathrm{L}$ do produto de reação em cadeia da polimerase de cada amostra foi adicionado individualmente a cada canaleta do gel, acrescido de $7 \mu \mathrm{L}$ da solução de carreamento. A eletroforese foi realizada a $100 \mathrm{~V}$ e $60^{\circ} \mathrm{C}$ por 16 horas. Os géis foram corados em solução de TAE $1 \mathrm{X}$ :brometo de etídio $(0,5 \mu \mathrm{g} / \mathrm{mL})$, analisados sob luz ultravioleta com captura de imagem por meio digital (Kodak 1D image Analysis).

A partir da análise dos amplicons detectados nas diferentes amostras, montou-se uma matriz de presença ou ausência e os tratamentos foram agrupados hierarquicamente por dendrograma, com base no seu perfil eletroforético. Para isso, utilizou-se o programa NTsyspc software, versão 2.0 para Windows.

\section{Resultados e Discussão}

Em cada coluna do gel de poliacrilamida, verificou-se o padrão de amplicons relativo à microbiota presente na digesta ileal de frangos de corte (Figura 1). Os amplicons de maior intensidade representam populações mais abundantes e as de menor intensidade, as menos abundantes.

Os aditivos foram capazes de alterar a microbiota da digesta ileal e as dietas com baixa energia favoreceram a existência de um número maior de amplicons (Figura 1), o

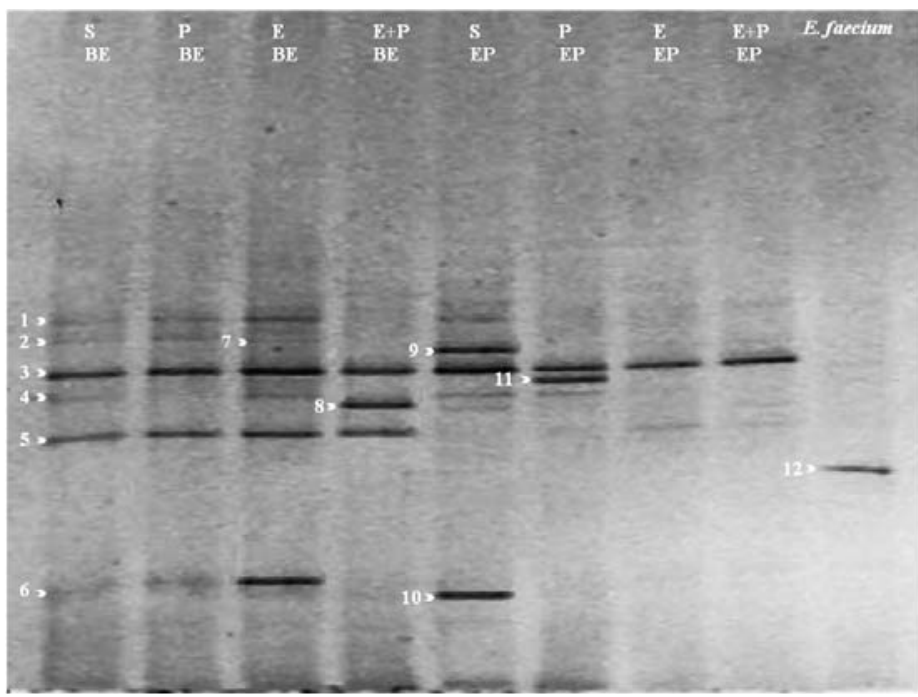

$\mathrm{BE}=$ baixa energia $; \mathrm{EP}=$ energia padrão $\mathrm{S}=$ sem aditivo $; \mathrm{P}=$ probiótico $; \mathrm{E}=$ enzima $; \mathrm{E}+\mathrm{P}=$ enzima + probiótico.

Figura 1 - Eletroforese em gel com gradiente desnaturante do produto da reação em cadeia da polimerase da região V3 do gene 16S do rRNA de amostras da digesta ileal de frangos de corte alimentados com dietas contendo dois níveis de energia, com ou sem aditivos. 
qual pode estar associado a maior diversidade de espécies presentes no lúmem ileal dos animais. Comparando à dieta com baixa energia sem aditivo com a dieta de baixa energia + probiótico, percebe-se que, no segundo caso, somente o amplicon 4 não foi detectado. Por outro lado, os demais amplicons (1, 2, 3, 5 e 6$)$ estiveram presentes em ambos os tratamentos, resultando em coeficiente de similaridade de aproximadamente $88 \%$ (Figura 2). Já a presença das enzimas na dieta com baixa energia favoreceu a presença do amplicon 7 , o reaparecimento do amplicon $4 \mathrm{e}$ o aumento na intensidade do amplicon 6 em relação à dieta com baixa energia sem enzimas. A dieta com baixa energia + enzimas apresentou coeficiente de similaridade em relação à sem enzimas e aquela com baixa energia + probiótico de aproximadamente 93 e $88 \%$, respectivamente. Todavia, quando em combinação com o probiótico, as enzimas favoreceram o aparecimento do amplicon 8, além da presença dos amplicons 3 e 5 , sendo esses últimos também encontrados em todas as dietas com baixa energia. Contudo, a combinação das enzimas com o probiótico foi capaz de inibir os amplicons 1, 2, 4, 6 e 7, encontrados na dieta com baixa energia com os mesmos aditivos em separado, resultando em uma similaridade bastante baixa (50\%).

$\mathrm{Na}$ dieta com energia padrão sem aditivo, foram observados os amplicons 1, 3, 4, 8, 9 e 10. Esta mesma dieta em associação com o probiótico favoreceu o aparecimento do amplicon 11 e a inibição dos amplicons $1,8,9$ e 10 . Apenas os amplicons 3 e 4 foram comuns aos dois tratamentos, resultando numa similaridade de aproximada- mente $45 \%$. A maior alteração microbiana nas dietas com energia padrão foi encontrada na presença do complexo enzimático em associação ou não com o probiótico. Esses tratamentos favoreceram apenas o predomínio dos amplicons 3 e 5, inibindo a presença dos outros amplicons encontrados nas demais dietas com energia padrão. Este perfil de amplicons resultou numa similaridade bastante baixa, de aproximadamente $37 \%$, em relação a todas as dietas com energia padrão.

O método de eletroforese em gel com gradiente desnaturante permitiu detectar 21 amplicons nas dietas com baixa energia, enquanto nas dietas com energia padrão 13 . Considerando a grande diversidade de amplicons encontrados em amostras intestinais de frango de corte indicada na literatura (Hume et al., 2006; Pedroso et al., 2006; Thompson et al., 2008), o número de amplicons observados neste trabalho pode ser considerado baixo. No entanto, esse resultado pode ser explicado pela comigração de alguns fragmentos com pares de bases pouco distintos (Jackson et al., 2002) ou conteúdo $\mathrm{C}+\mathrm{G}$ bastante semelhantes (Simpson et al., 1999). Zhu \& Joerger (2003) visualizaram por eletroforese em gel com gradiente desnaturante 20 amplicons, mas, após técnicas de clonagem e sequenciamento, identificaram 243 sequências diferentes de bactérias presentes no conteúdo cecal de frangos de corte. Assim, menos amplicons não significam necessariamente menos espécie bacterianas, mas espécies com conteúdo molecular mais semelhante.

Os resultados indicam que a dieta com baixa energia apresentou 8 amplicons a mais em comparação à dieta com

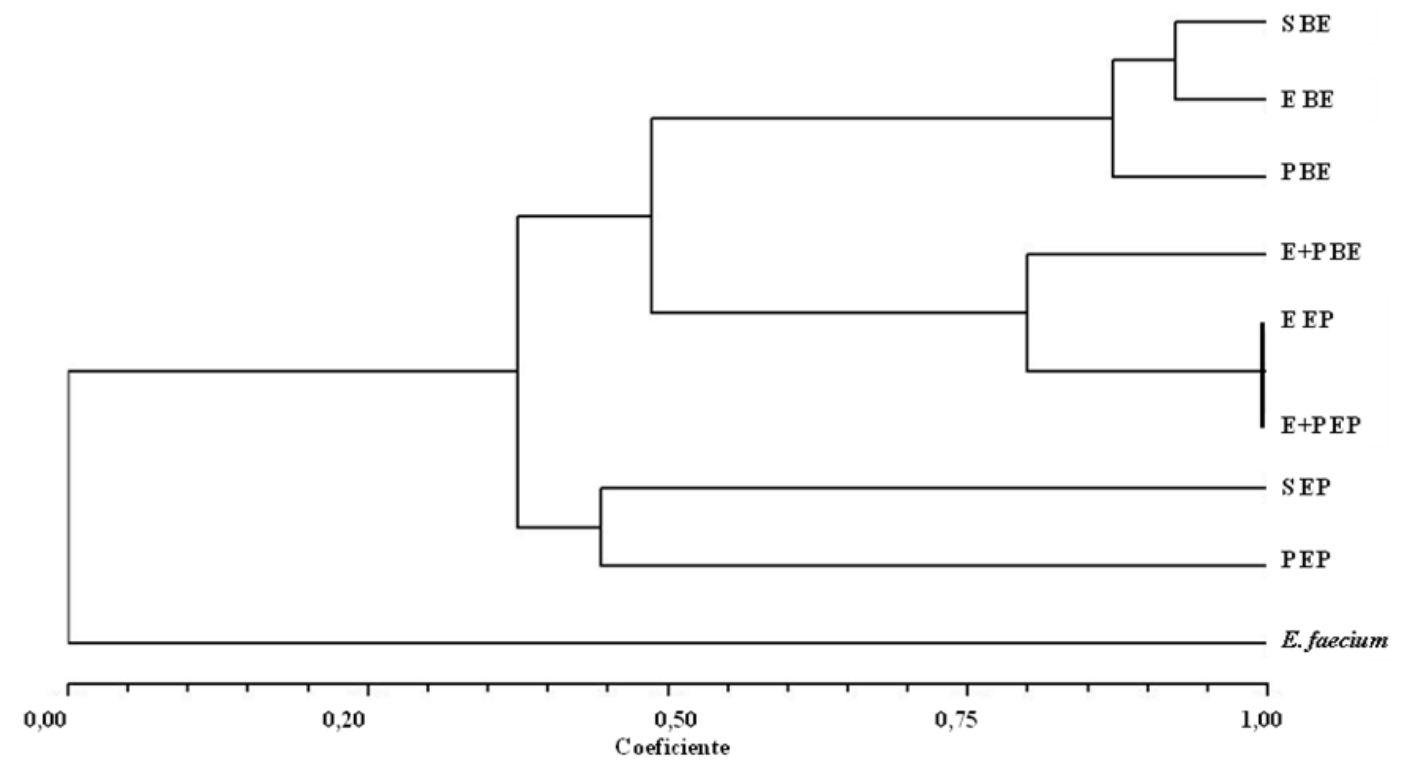

$\mathrm{BE}=$ baixa energia $; \mathrm{EP}=$ energia padrão $\mathrm{S}=$ sem aditivo $; \mathrm{P}=$ probiótico $; \mathrm{E}=$ enzima $; \mathrm{E}+\mathrm{P}=$ enzima + probiótico.

Figura 2 - Dendrograma dos amplicons obtidos por eletroforese em gel com gradiente desnaturante do produto da reação em cadeia da polimerase da região V3 do gene $16 \mathrm{~S}$ do rRNA de amostras da digesta ileal de frangos de corte alimentados com dietas contendo dois níveis de energia, com ou sem aditivos. 
energia padrão. A dieta com baixa energia apresentou farelo de trigo em sua composição, ingrediente com grande quantidade de polissacarídeos não-amiláceos solúveis (PNA). Normalmente, os PNA diminuem o trânsito de passagem da digesta no trato intestinal a ponto de os microrganismos serem capazes de competir por nutrientes com o animal, tendo dessa forma mais condições para sua reprodução e aumento populacional (Shakouri et al., 2009). Contudo, mesmo encontrando-se um número maior de amplicons nas dietas com baixa energia, não se pode afirmar que apresentam maior número de espécies microbianas.

No probiótico adicionado às dietas, foi encontrado o amplicon 12. No entanto, a presença deste amplicon não foi constatada em quaisquer tratamentos avaliados. Contudo, houve outras alterações na microbiota da dieta com energia padrão com probiótico em combinação ou não com as enzimas. Nas dietas com baixa energia, essa alteração ocorreu apenas quando o probiótico foi utilizado em associação com as enzimas. É possível que a dieta com baixa energia prejudique o desenvolvimento do probiótico, um efeito menos expressivo quando em associação com as enzimas. Em geral, os probióticos promovem efeitos antagônicos ou sinérgicos em relação à microbiota presente no tratogastrointestinal, provavelmente devido às várias bacteriocinas que produzem, mantendo-se em nível de colonização. Todavia, neste trabalho, o probiótico não foi suficientemente competitivo para manter-se em quantidade expressiva a ponto de colonizar o lúmen ileal.

\section{Conclusões}

Os aditivos usados nas dietas para frangos de corte são capazes de alterar a microbiota do lúmen íleal, porém o probiótico utilizado não é eficiente em colonizar o trato ileal desses animais.

\section{Referências}

APAJALAHTI, J.H.A.; KETTUNEN, A.; BEDFORD, M.R. et al. Percent $\mathrm{G}+\mathrm{C}$ profiling accurately reveals diet-related differences in the gastrointestinal microbial community of broiler chickens. Applied Environmental Microbiology, v.67, p.5656-5667, 2001.

APAJALAHTI, J. Comparative gut microflora, metabolic challenges, and potential opportunities. Journal of Applied Poultry Research, v.14, p.444-453, 2005.

CHOCT, M.; HUGHES, R.J.; BEDFORD, M.R. Effects of a xylanase on individual bird variation, starch digestion throughout the intestine, and ileal and cecal volatile fatty acid production in chickens fed wheat. British Poultry Science, v.40, p.419-422, 1999.

HUME, M.E.; CLEMENTE-HERNÁNDEZ, S.; OVIEDO-RONDÓN, E.O. Effects of feed additives and mixed Eimeria species infection on intestinal microbial ecology of broilers. Poultry Science, v. 85, p.2106-211, 2006.

JACKSON, M.D.; GOULD, S.J.; ZABRISKIE, T.M. Studies on the formation and incorporation of streptolidine in the biosynthesis of the peptidyl nucleoside antibiotic streptothricin F. The Journal of Organic Chemistry, v.67, p.2934-2941, 2002.

MUYZER, G.; WAAL, E.C.; UITTERLINDEN, A.G. Profiling of complex microbial populations by denaturing gradient gel electrophoresis analysis of polymerase chain reaction amplified genes coding for 16S rRNA. Applied Environmental Microbiology, v.59, p.695-700, 1993.

OVIEDO-RONDÓN, E.O.; HUME, M.E.; HERNÁNDEZ, C. et al. Intestinal microbial ecology of broilers vaccinated and challenged with mixed Eimeria species, and supplemented with essential oil blends. Poultry Science, v.85, p.854-860, 2006.

PEDRoso, A.A.; MENTEN, J.F.M.; LAMBAIS, M.R. The structure of bacterial community in the intestines of newly hatched chicks. Journal of Applied Poultry Research, v. 15, p.232-237, 2005.

PEDROSO, A.A.; MENTEN, J.F.M.; LAMBAIS, M.R. et al. Intestinal bacterial community and growth performance of chickens fed diets containing antibiotics. Poultry Science, v.85, p.747-752, 2006 .

ROSTAGNO, H.S.; ALBINO, L.F.T.; DONZELE, J.L. et al. Tabelas brasileiras para aves e suínos: composição de alimentos e exigências nutricionais. 2.ed.Viçosa, MG: UFV, 2005. 186p.

SHAKOURI, M.D.; IJI, P.A.; MIKKELSEN, L.L. et al. Intestinal function and gut microflora of broiler chickens as influenced by cereal grains and microbial enzyme supplementation. Animal Physiology and Animal Nutrition, v.93, 647-658, 2009.

SIMPSON, J.M.; MCCRACKEN, V.J.; GASKIN, H.R. et al. Application of denaturant gradient gel electrophoresis for the analysis of the porcine gastrointestinal microbiota. Journal of Microbiological Methods, v.36, p.167-179, 1999.

THOMPSON, K.; BURKHOLDER, K.; PATTERSON, J. et al. Microbial ecology shifts in the ileum of broilers during feed withdrawal and dietary manipulations. Poultry Science, v.87, p. 1624-1632, 2008.

ZHU, X.Y.; JOERGER, R.D. Composition of microbiota in content and mucus from cecae of broiler chickens as measured by fluorescent in situ hybridization with group-specific, 16S rRNA-targeted oligonucleotide probes. Poultry Science, v. 82, p.1242-1249, 2003. 